\title{
Modeling of Thermal Responsiveness of Automatic Sprinklers
}

GUNNAR HESKESTAD and ROBERT G. BILL, JR.

Factory Mutual Research Corporation

1151 Boston-Providence Turnpike

Norwood, Massachusetts 02062, USA

ABSTRACT

Predictions according to a thermal response model for sprinklers, modified to account for heat loss by conduction to the sprinkler mount, have been successfully tested against response of 13 sprinkler models in room fire experiments. Sprinkler characteristics entering the response model include the Response Time Index and a conduction parameter, both measured in a hot-air tunnel. The conduction parameter did tend to rise with increasing temperature of the mount, reflecting some departure, although not significant, from ideal behavior.

KEY WORDS: Automatic Sprinklers; Response Model; Conduction Heat Loss .

\section{INTRODUCTION}

Automatic sprinklers continue to play a key role in modern fire protection. In recent years, it has become increasingly more important to be able to predict the actuation of sprinklers in given fire situations. This capability is especially needed in applications where a slow response can render an otherwise adequate sprinkler system ineffective, as in residential systems and ESER systems (Early Suppression, East Response). This paper reviews recent developments in modeling the thermal response of automatic sprinklers and presents results from extensive experiments to verify the model. Particular emphasis is placed on the conductive heat loss from the heat-responsive element, the importance of which has become apparent only in recent years.

Heat-responsive elements of sprinklers exist in many forms but are basically of two types: metal linkages stabilized with soldered joints and liquid-filled glass bulbs. As the element, or element assembly, heats up under fire conditions, the solder melts or the glass bulb ruptures near a design temperature rating, which releases the restraining force on the sprinkler water valve and allows water to flow.

\section{EARLY RESPONSE MODEL}

An early response model(1) assumed 1) that the heat responsive element is heated purely by forced convection; 2) that all heat transferred to the element is stored there, with no conductive heat loss to supporting structure; 3 ) that the element heats isothermally; and 4) that no additional heat is required to actuate the element, such as heat of fusion for solder-type sprinklers. The heat balance on the element is then: 
$\operatorname{mc}\left(d \mathrm{~T}_{\mathrm{e}} / \mathrm{dt}\right)=h A\left(\mathrm{~T}_{\mathrm{g}}-\mathrm{T}_{\mathrm{e}}\right)$

where $m=$ mass of element,

$c=$ specific heat of element, assumed invariant with temperature,

$\mathrm{h}=$ convective heat transfer coefficient,

$A=$ surface area of element,

$\mathrm{T}_{\mathrm{e}}=$ temperature of element,

$\begin{aligned} T_{g}^{e} & =\text { gas (essentially air) temperature, } \\ t^{g} & =\text { time. }\end{aligned}$

Expressing temperatures relative to the initial (ambient) temperature $\mathrm{T}_{0}$, and rear ranging, eq (1) becomes:

$d\left(\Delta \mathrm{T}_{\mathrm{e}}\right) / \mathrm{dt}=\tau^{-1}\left(\Delta \mathrm{T}_{\mathrm{g}}-\Delta \mathrm{T}_{\mathrm{e}}\right)$

where $\Delta \mathrm{T}_{\mathrm{e}}=\mathrm{T}_{\mathrm{e}}-\mathrm{T}_{\mathrm{o}}$,

$\begin{aligned} \Delta T_{g} & =T_{g}^{-T}{ }^{-T} \\ \tau & =m \& / h A\end{aligned}$

Equation (2) is the temperature-response equation of the sensing element, which can be solved once $\Delta \mathrm{T}_{g}(t)$ and $\tau(t)$ are specified, together with initial conditions ( $\left.\Delta \mathrm{T}_{\mathrm{e}}(\mathrm{t}=0)=0\right)$.

The quantity $\tau$ is the time constant of the element which, for a given element, depends only on the convective heat-transfer coefficient, $h$. From experimental correlations of Nusselt number versus Reynolds number for bluff objects resembling heat-responsive elements, along with the known dependence on temperature of the thermal, conductivity and kinematic viscosity of air, it has been shown (1) that $h$ o $u^{1 / 2}$, independent of air temperature, where $u$ is the gas velocity. From the definition of $\tau$ under eq (2), it follows that:

$\tau u^{1 / 2}=$ constant.

The term "Response Time Index," or RTI, has been adopted (2) for this product, i.e.:

$\mathrm{RTI}=\mathrm{ru}^{1 / 2}$,

in terms of which eq (2) can be written:

$d\left(\Delta T_{e}\right) / d t=\left(u^{1 / 2} / R T T\right)\left(\Delta T_{g}-\Delta T_{e}\right)$.

Given the RTI, which in principle is constant for a sprinkler at a given orientation to the flow, together with $\Delta T_{g}$ and $u$ as functions of time, the thermal response $\Delta \mathrm{T} \mathrm{e}^{(t)}$ can be calculated. Sprinkler actuation occurs when $\Delta \mathrm{T}$ e $=\Delta T_{e a}$, where $\Delta T_{e a}$ is the actuation temperature (temperature rating) of the heat responsive element above ambient.

An examination(1) of the various assumptions of the early response theory indicated that most were acceptable. However, the assumption that the conductive heat loss from the element was negligible was not resolved because of the difficulty of estimating these losses.

The constancy of RTI was first investigated(1) using conventional-response spripklers; fast-response sprinklers had not yet entered the market. A plunge test " was adopted for measuring RTI, where in the sprinkler is suddenly immersed in the steady flow of the horizontal test section of a hot-air tunnel. For a

\footnotetext{
*A ramp test has been used by others $(3,4)$, where the test sprinkler is exposed to a linear rate of rise in gas temperature.
} 
plunge test, the solution of eq (5) can be written in the following form for RTI:

$$
\operatorname{RTI}=\frac{-t_{r} u^{1 / 2}}{\ln \left(1-\Delta T_{e a} / \Delta T_{g}\right)} .
$$

Here, $t_{r}$ is the response or actuation time; $u$ is the gas (air) velocity in the test section; $\Delta \mathrm{T}_{e a}$ is $\Delta \mathrm{T}_{\mathrm{e}}$ at actuation (temperature rating from liquid bath test relative to ambient temperature prior to plunge); and $\Delta \mathrm{T}_{\mathrm{g}}$ is the gas temperature relative to the ambient temperature. Above certain gas temperature limits(1) where radiant heat exchange between sprinkler and tunnel walls is insignificant, ten different sprinkler models individually responded with fairly constant RTI over the velocity range $1.5-5.2 \mathrm{~m} / \mathrm{s}$ and the temperature range $125-430^{\circ} \mathrm{C}$. The insensitivity of RTI to gas temperature in these experiments may be interpreted to mean that the heat of fusion of the solder for the solder-type sprinklers was not important ${ }^{*}(5)$. Furthermore, none of the (small) variations observed in RTI could be attributed to conduction heat loss.

Based on the first experimental program, a special plunge-test tunnel was designed and calibrated for further work $(1,2)$, which still serves as a basic tool for sprinkler response research at Factory Mutual Research Corporation.

\section{INCORPORATION OF CONDUCTIVE HEAT LOSS}

Recently, Pepi $(7,8)$ provided the first unambiguous proof that conductive heat loss from the heat responsive element to the sprinkler support structure may significantly affect sprinkler response, especially at low gas velocities. He established this behavior in both plunge tests and fire tests, using sprinklers with adjustable thermal insulation between the heat responsive element and its support. Soon thereafter, the response theory presented in Section 2 was modified to accommodate conductive heat loss(5); the modification is briefly reviewed in this section.

The simplest possible form of conductive heat loss rate was assumed, proportional to the temperature difference between the heat responsive element and the sprinkler fitting, the latter first assumed to remain at ambient temperature. The conductive heat loss term $C^{\prime}\left(\mathrm{T}_{\mathrm{e}}^{-\mathrm{T}_{0}}\right)$, where $\mathrm{C}^{\prime}$ is a constant for a given sprinkler, subtracts from the right-hand side of eq (1). In further developments, it is convenient to define a new constant $C$ :

$\mathrm{C}=\mathrm{C}^{\prime} \cdot \mathrm{RTI} /(\mathrm{mc})$,

where $C$ is a conduction parameter characteristic of the sprinkler. The modified form of eq (5) then becomes:

$$
\frac{\mathrm{d}\left(\Delta_{\mathrm{T}}\right)}{\mathrm{dt}}=\frac{\mathrm{u}^{1 / 2}}{\mathrm{RTI}}\left[\Delta \mathrm{T}_{\mathrm{g}}-\left(1+c / \mathrm{u}^{1 / 2}\right) \Delta \mathrm{T} \mathrm{e}\right] \text {. }
$$

Hence, instead of a one-parameter response equation in RTI, we now have a twoparameter response gquation in RTI and C. Conveniently, while the units of RTI are (Length.Time) $1 / 2$, the units of $C$ are (Length/Time) $1 / 2$.

Equation (8) can be transformed into a very useful form whenever the gas velocity, $u$, is constant, as in a plunge test, or does not change sufficiently rapidly with time (appears to be practically always the case in fire situations). Then eq ( 8$)$ can be written:

*Evans and Madrzykowski(6) have also addressed this question. 
$\mathrm{d}(\Delta \mathrm{T} e v) / d t=\left(u^{1 / 2} / \mathrm{RTI}_{\mathrm{v}}\right)\left[\Delta \mathrm{T}_{\mathrm{g}}-\Delta \mathrm{T}_{\mathrm{ev}}\right]$

where:

$\Delta \mathrm{T}_{\mathrm{ev}}=\left(1+\mathrm{C} / \mathrm{u}^{1 / 2}\right) \Delta \mathrm{T}_{\mathrm{e}}$,

$\mathrm{RTI}_{\mathrm{V}}=\mathrm{RTI} /\left(1+\mathrm{C} / \mathrm{u}^{1 / 2}\right)$.

Note that eq (9) is precisely in the form of the original model response relation, eq (5), where $\Delta T_{e}$ is replaced by $\Delta T_{e v}$ and RT I is replaced by $\mathrm{RTI}_{\mathrm{V}}$. The quantity $\Delta \mathrm{T}_{\text {ey }}$ can be considered as a virtual temperature rise of the heatresponsive element, and $\mathrm{RTI}_{\mathrm{v}}$ can be considered as a virtual RTI.

The solution of eq (9) for a plunge test (or fire generating constant temperature and velocity) is obtained from eq ( 6 ) by replacing RTI with RTI $v$ and $\Delta \mathrm{T}_{\text {ea }}$ with $\Delta \mathrm{T}$ eva. The result is:

$$
\frac{\mathrm{RTI}}{1+C / \mathrm{u}^{1 / 2}}=\frac{-t_{\mathrm{r}} \mathrm{u}^{1 / 2}}{\ln \left(1-\Delta \mathrm{T}_{\mathrm{ea}}\left(1+\mathrm{C} / \mathrm{u}^{1 / 2}\right) / \Delta \mathrm{T}_{\mathrm{g}}\right)} .
$$

Suppose that the sprinkler fitting does not remain at ambient temperature during the fire exposure. This situation can be easily handled in terms of the temperature rise of the fitting, $\Delta \mathrm{T}_{\mathrm{f}}=\mathrm{T}_{\mathrm{f}}-\mathrm{T}_{0}$. Tracing the effect of carrying the conduction heat loss term as $C^{\prime}\left(T_{e}-T_{f}\right) \stackrel{T^{\prime}}{=} C^{\prime} \Delta T_{e}-C^{\prime} \Delta T_{f}$ (rather than $C^{\prime}\left(T_{e}\right.$ $\left.\left.T_{o}\right)=C^{\prime} \Delta T_{e}\right)$, one establishes simple corrections to eqs (8) and (9). The corrections consist of simply writing $\Delta \mathrm{T}_{\mathrm{g}}$ as $\Delta \mathrm{T}_{\mathrm{g}}+\Delta \mathrm{T}_{\mathrm{gf}}$, where:

$\Delta \mathrm{T}_{\mathrm{gf}}=\left(\mathrm{C} / \mathrm{u}^{1 / 2}\right) \Delta \mathrm{T}_{\mathrm{f}}$

One anticipated effect of the conduction heat loss can be assessed via eq (8). Clearly, heating of the heat-responsive element is retarded as the conduction term $\mathrm{C} / \mathrm{u}^{1 / 2}$ increases, either as a result of an increase in the conduction parameter, $\mathrm{C}$, or a decrease in the gas velocity. Another effect is anticipated from eq (9) where it is evident that in a steady temperature environment, the virtual temperature $r$ ise of the element, $\Delta \mathrm{T}$ ey, can only $r$ ise to the value $\Delta \mathrm{T}_{\mathrm{g}}$; in turn, the actual temperature rise is limlted to the value (using eq $(10))$ ?

$\Delta \mathrm{T}_{\mathrm{e}}=\Delta \mathrm{T}_{\mathrm{g}} /\left(1+\mathrm{C} / \mathrm{u}^{1 / 2}\right)$.

\section{TEST OF MODIFIED MODEL}

An experimental program incorporating 13 sprinkler models was conducted to investigate the efficacy of the response model as modified. The program consisted of two parts, 1) a laboratory determination of the RTI value and the conduction parameter $\mathrm{C}$ and 2) room fire tests comparing actual response times to predictions based on the model and laboratory values of RTI and C.

Determination of RTI and C

Values of RTI and $C$ were determined in the FMRC plunge test tunnel(2).

All the selected sprinklers were temperature rated near $73^{\circ} \mathrm{C}$, for which the minimum test temperatures to preclude significant radiant heat exchange with the tunnel walls is $(1,2,5) 118^{\circ} \mathrm{C}$. There was a second consideration in the measurements of RTI in plunge tests, the desirability of avoiding a 
significant temperature increase of the sprinkler mount, which would have complicated the RTI determination. This consideration led to the design of a rather massive sprinkler mount, combined with the relatively high plunge test temperature of $191^{\circ} \mathrm{C}$ and a (standard) plunge test velocity of $2.56 \mathrm{~m} / \mathrm{s}$.

The sprinkler mount, made of brass, is illustrated in Figure 1 as installed in the test section cover plate (several of these combinations were available). The sprinkler under test was screwed into the mount at $A$, and an air line, pressurizing the space above the sprinkler valve to $41 \mathrm{kPa}$, was attached at threaded connection B. A well for a thermocouple was provided at $C$; the thermocouple was held in place in the well with an electrically nonconducting cement of high thermal conductivity. Threaded connection $D$ was provided later in one of the mounts for subsequent measurements of the conduction parameter. The mount was thermally insulated from the cover plate.

As described elsewhere $(1,2)$, the test cover is hinged to the upstream end of the test section opening. The sprinkler is plunged into the test stream as the cover is closed, simultaneously starting a timer. When the sprinkler actuates, the air pressure is relieved, which stops the timer.

Reference to eq (12) indicates that the plunge test alone is not sufficient for determining RTI when there is a conductive heat loss. The conduction parameter, $\mathrm{C}$, had to be determined first. This parameter was measured in a test where the sprinkler mount was held at constant temperature over a prolonged period by circulating cold (tap) water through the mount, admitting water at the threaded connection $D$ in Figure 1 and discharging the water at threaded connection $B$. The waterway was essentially dry, being plugged with a rubber stopper to prevent cooling water from entering the tunnel test section when the sprinkler operated. The steady-state temperature rise (referenced to the mount temperature) of the heat-responsive element is given by eq (14). If the gas velocity is increased to a higher value from one prolonged exposure to the next, the steady state temperature $r$ ise of the element increases. For a sufficiently high air velocity, $u_{c}$, the element will just actuate in a prolonged exposure. At that point:

$\Delta \mathrm{T}_{\mathrm{g}} /\left(1+\mathrm{C} / \mathrm{u}_{\mathrm{c}}{ }^{1 / 2}\right)=\Delta \mathrm{T}_{\mathrm{ea}}$

which can be solved for $C$. In order to determine $u_{c}$, a series of standard test velocities were selected for the plunge test tunnel, the square root of the ratio of sequential test velocities being fixed at 1.10 . For each test

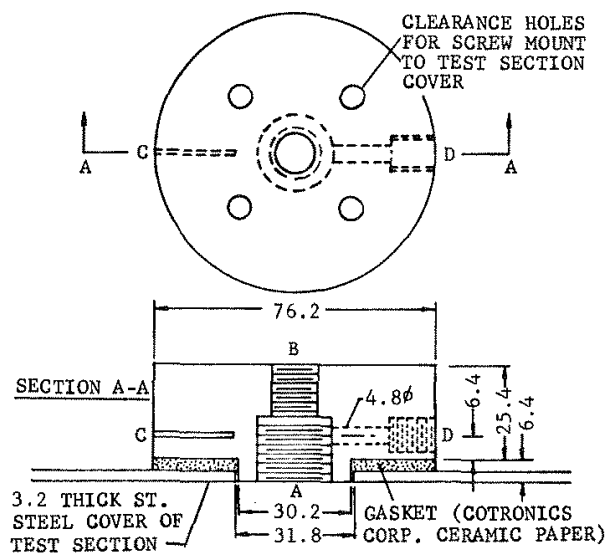

Eigure 1 Brass sprinkler mount installed in the test section cover of the plunge test tunnel and used in the plunge tests. Dimensions in $\mathrm{mm}$. 
Table 1 RTI Values and Conduction Parameters of Selected Sprinkler Models

\begin{tabular}{|c|c|c|c|c|c|}
\hline $\begin{array}{l}\text { Sprinkler } \\
\text { Model }\end{array}$ & $\begin{array}{l}\text { Solder (S) } \\
\text { or Bulb (B) }\end{array}$ & $\begin{array}{l}\text { Actuation } \\
\text { Temp. }\left({ }^{\circ} \mathrm{C}\right) \\
\end{array}$ & $\begin{array}{c}\theta \\
(\mathrm{deg})\end{array}$ & $\left(\mathrm{m}^{1 / 2} \cdot \mathrm{s}^{1 / 2}\right)$ & $\left(\mathrm{m}^{\left.1 / \mathrm{C}^{\mathrm{a}} / \mathrm{s}^{1 / 2}\right)}\right.$ \\
\hline$A$ & $s$ & 73 & 90 & 123 & 0.82 \\
\hline " & $"$ & " & 45 & 131 & $(0.87)$ \\
\hline$"$ & " & " & $22 \quad 1 / 2$ & 145 & $(0.96)$ \\
\hline$"$ & " & " & $111 / 4$ & 163 & $(1.08)$ \\
\hline$"$ & $"$ & " & 0 & 192 & $(1.27)$ \\
\hline B & B & 73 & 90 & 172 & 0.88 \\
\hline C & $S$ & 73 & 90 & 135 & 0.99 \\
\hline D & $S$ & 73 & 90 & 25.3 & 0.53 \\
\hline $\mathrm{E}$ & $S$ & 73 & 90 & 113 & 0.83 \\
\hline $\mathrm{F}$ & $S$ & 73 & 90 & 27.5 & 0.58 \\
\hline G & $S$ & 73 & 90 & 31.0 & 0.91 \\
\hline $\mathrm{H}$ & $S$ & 73 & 90 & 113 & 1.17 \\
\hline I & $S$ & 73 & 90 & 183 & 0.80 \\
\hline$J$ & $S$ & 73 & 90 & 203 & 1.52 \\
\hline $\mathrm{K}$ & $S$ & 73 & 90 & 25.2 & 0.52 \\
\hline $\mathrm{L}$ & B & 70 & 90 & 199 & 0.90 \\
\hline$"$ & " & " & 45 & 206 & $(0.93)$ \\
\hline$"$ & " & $"$ & $221 / 2$ & 235 & $(1.06)$ \\
\hline$"$ & $"$ & $"$ & 0 & 305 & $(1.38)$ \\
\hline M & B & 72 & 90 & 130 & 0.60 \\
\hline
\end{tabular}

${ }^{a}$ Conduction coefficients measured with sprinklers in original water-cooled mount; mount temp. in range $12-19^{\circ} \mathrm{C}$. Values in parentheses have been calculated from result at $\theta=90^{\circ}$ and $\mathrm{C} \propto \mathrm{RTI}$.

velocity, a sprinkler was exposed for 10 minutes (deemed sufficient to establish steady state element temperature) until actuation was bracketed between two successive test velocities. The conduction parameter was taken as the average of the values $C$ calculated for the bracketing velocities, using eq (15). Hence, the conduction parameter in this procedure was bracketed within a tolerance of \pm 5 percent. In order not to require unreasonably low air velocities, the fairly low test temperature of $127^{\circ} \mathrm{C}$ was chosen, which is still above the limit where radiant heat exchange between sprinklers and tunnel walls is insignificant $\left(118^{\circ} \mathrm{C}\right.$ for the actuation temperature of the sprinklers near $\left.73^{\circ} \mathrm{C}\right)$.

Results of RTI and C values for the 13 selected sprinklers, coded A through $M$, are listed in Table 1. The fourth column indicates the angle $\theta$ between the approach flow and the plane of the sprinkler frame. Most of the measurements were made with the plane of the sprinkler frame perpendicular to the approach flow, $\theta=90^{\circ}$. (When the actuation mechanism was not symmetric with respect to the plane of the sprinkler frame, $\theta=90^{\circ}$ corresponded to the orientation having the greater mass of the actuation mechanism downstream of this plane). However, two sprinkler models were investigated at several orientations, $A$ and $L$; in these cases it is observed that the RTI increased as $\Theta$ approached 0 , i.e., as the heat responsive elements were exposed more and more to the wake generated by the sprinkler frame. Four of the sprinklers were designed for fast response, $D, F, G$ and $K$, and it is seen that these sprinklers had considerably lower RTI values than the others. The last column in Table 1 lists values of the conduction parameter, $C$, based on measurements at $\theta=$ $90^{\circ}$. Values listed at other orientations for sprinklers $A$ and $L$ have been calculated from the measurements at $\theta=90^{\circ}$ and the proportionality $\mathrm{C} \propto \mathrm{RTI}$ implied by eq (7) for a given sprinkler.

The $C$ value measurements in T'able 1 were conducted with constant mount temperatures which varied in the range $12-19^{\circ} \mathrm{C}$ from test to test, depending on 
the temperature of the tap water at the time of the test. This system was subsequently improved to generate any desired mount temperature within a reasonable range, using a bypass loop with a cooling coll immersed in ice water. Figure 2 shows results of conduction parameter versus mount temperature, using the improved system, for some of the sprinkler models. Ideally, the conduction parameter should have been independent of the mount temperature, which was not quite the case. There was usualiy a slight increase in $\mathrm{C}$ with the mount temperature.

One suspects that a number of variables along the conduction path may affect the magnitude of $C$, such as mounting torque, depth of thread engagement, the fitting material and sealant, and whether or not the sprinkler waterway is filled with water. A recent study (9) has indicated that such effects are generally small.

\section{Room Fire Tests}

The room fire tests employed a test room within a larger test building, Figure 3. There was only one opening to the room, an open door at one end. A fire source was placed near the opposite end, and ceiling sprinklers together with associated instruments were located at distances from the fire source of 1.63 and $4.55 \mathrm{~m}$. Each ceiling station incorporated two sprinklers, screwed into $1 / 2 \mathrm{in.}$ (steel) pipe couplings extending down $0.038 \mathrm{~m}$ from the ceiling, attached to pipe nipples above the roof. Each nipple was fitted to the center of a water reservoir, consisting of a $1.6 \mathrm{~m}$ long, $1 \mathrm{in}$. diameter horizontal steel pipe above the roof with $0.13 \mathrm{~m}$ high risers open to the atmosphere at both ends. After a sprinkler had been installed for testing, the pipe to which it was mounted was filled with water. A thermocouple monitored the water temperature within the waterway of each sprinkler. To record the actuation times, metal electrodes were positioned in the path of the weak spray produced when the sprinklers actuated, the spray completing an electric circuit which was monitored. Along with the two sprinklers at a ceiling station, there were two thermocouples to measure gas temperature and one bidirectional flow probe

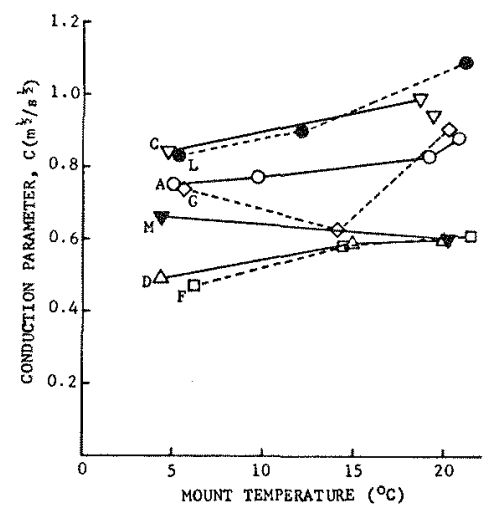

Figure 2 Effect of sprinkler mount temperature on conduction parameter, using original watercooled mount $\left(\theta=90^{\circ}\right)$.

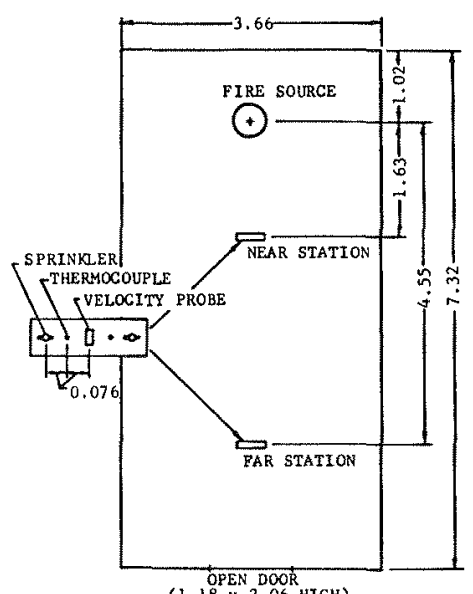

Figure 3 Fire room with two sprinkler and instrument stations at the ceiling. Dimensions in $\mathrm{m}$. 
(10) (connected to electronic manometer) to measure gas velocity, all at a sensing level of $0.076 \mathrm{~m}$ beneath the ceiling, very nearly the level of the center of the heat responsive element of each sprinkler.

As fire source was used either a $0.46 \mathrm{~m}$ diameter pool of heptane floated on water or an oven dried wood crib (pine) measuring $0.51 \mathrm{~m} \times 0.51 \mathrm{~m} \times 0.38 \mathrm{~m}$ high, made from $19 \mathrm{~mm}$ square sticks ( 8 sticks per layer, 20 sticks high). Remote ignition with an electric match was employed, in the case of the wood crib, via a $0.10 \mathrm{~m} \mathrm{dia.} \mathrm{pan} \mathrm{of} \mathrm{heptane} \mathrm{underneath} \mathrm{the} \mathrm{central} \mathrm{shaft} \mathrm{of} \mathrm{the}$ crib. Both fire sources were continuously weighed on load platforms to monitor mass-loss rate. The ceiling clearances above the fire sources were $2.24 \mathrm{~m}$ for the heptane pool and $1.90 \mathrm{~m}$ for the wood crib.

The mass loss rate of the heptane pool typically reached steady state after $25-30 \mathrm{~s}$ at a heat release rate of approximately $130 \mathrm{~kW}$ [assuming a combustion efficiency of $85 \%$ (11)]. The wood crib fires grew with the second power of time according to [assuming an actual heat of combustion of $12,500 \mathrm{~kJ} / \mathrm{kg}(11)]$ :

$Q(k W)=1000\left[\left(t-t_{0}\right) / t_{g}\right]^{2}$

where the "growth time", $t_{g}$, was about $260 \mathrm{~s}$ and the effective ignition time, $t_{0}$, was near $30 \mathrm{~s}$.

Typical measurements of gas temperatures and velocities have been presented elsewhere(5).

Response times were calculated on a computer from eq (8), replacing $\Delta \mathrm{T}_{\mathrm{g}}$ by $\Delta \mathrm{T}_{\mathrm{g}}+\Delta \mathrm{T}_{\mathrm{gf}}$ according to eq (13) to account for heating of the sprinkler fieting, and using RTI and $C$ values from Table 1. Scan-to-scan data of $T_{g}$, * $\mathrm{u}$ and $\mathrm{T}_{\mathrm{f}}$, recorded at one scan per second, were employed in the calculations ${ }^{*}$.

Figure 4 presents calculated response times versus experimental response times for the pool fires. Data points pertaining to sprinkler orientations other than $\theta=90^{\circ}$ have been identified; e.g., A22.5 pertains to sprinkler model $A$ oriented at $\theta=22.5^{\circ}$. The data scatter moderately about the Iine for perfect correlation. Repetition of the calculations using $C=0$ has indicated that most of the calculated response times associated with the far station are very sensitive to the conduction parameter. For example, in one case a sprinkler never actuated at the far station (Sprinkler J), which was confirmed by the calculations using the RTI and $C$ values in Table 1 ; however, assuming $C$ $=0$, the calculated response time was $253 \mathrm{~s}$.

Next, consider the results from the wood crib fires in Figure 5, all pertaining to the orientation $\theta=90^{\circ}$. Here the scatter about the line for perfect correlation is very small. The largest deviation of calculated from experimental response time is 8 percent. Calculations with $\mathrm{C}=0$ gave a maximum deviation of 16 pereent, the largest deviations occurring for the lower-RTI sprinklers.

Theoretical calculations of sprinklers response, using the modified response model(5), have indicated that conductive heat loss effects are important primarily at low gas temperatures and velocities, as in the low heatrelease-rate pool fires of this program. For rising temperatures and velocities, as in growing fires, it was found that conduction effects become increasingly more important as RTI decreases and fire growth becomes slower.

*Hand calculations based on eq ( 9 ) and using smoothed curves of $\mathrm{T}_{\mathrm{g}}$, $u$ and $\mathrm{T}_{\mathrm{f}}$ versus time gave very similar results. 


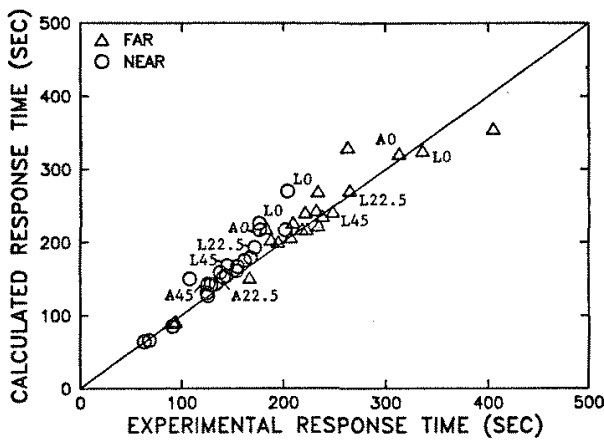

Figure 4 Pool fires: Calculated versus experimental sprinkler response times at $\theta=90^{\circ}$, except as indicated for sprinklers $A$ and $L$.

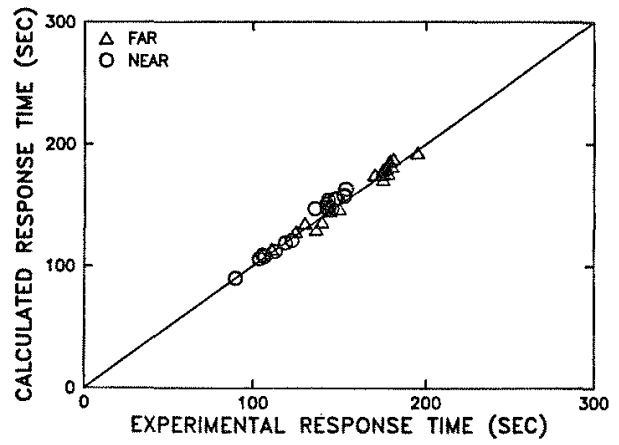

Figure 5 wood crib fires: Calculated versus experimental sprinkler response times $\left(0=90^{\circ}\right)$.

\section{CONCLUSIONS}

1. Response times of 13 different sprinklers in realistic room fire experiments were consistent with calculations according to a modified sprinkler response model, which accounts for conductive heat loss to the sprinkler mount. The 13 sprinklers included two which were investigated at several orientations to the gas flow. Sprinkler characteristics needed for the calculations, RTI and the conduction parameter $\mathrm{C}$, were measured in plunge tests and "prolonged exposure" tests, respectively, in the FMRC plunge test tunnel.

2. According to the modified sprinkler response model, conductive heat loss effects are primarily important at low gas temperatures and velocities. For rising temperatures and velocities, as in growing fires, conduction effects become increasingly more important as RTI decreases and fire growth becomes slower.

3. The conduction parameter did tend to rise with increasing temperature of the sprinkler mount, reflecting some departure from ideal behavior.

\section{REFERENCES}

1. Heskestad, G. and Smith, H.F., "Investigation of a New Sprinkler Sensitivity Approval Test: The Plunge Test," FMRC J.I. 22485, Factory Mutual Research Corporation, Norwood, Massachusetts, December 1976.

2. Heskestad, G. and Smith, H.F., "Plunge Test for Determination of Sprinkler Sensitivity," FMRC J.I. 3A1E2.RR, Factory Mutual Research Corporation, Norwood, Massachusetts, December 1980.

3. Thorne, P.F., Melinek, S.J. and Theobald, C.R., "The Thermal Performance of Sprinkler Heads," Fire Detection and Suppression Symposium, Society of Fire Protection Engineers, Linthicum Heights, Maryland, March 9-11, 1987.

4. Theobald, C.R., "Thermal Response of Sprinklers. Part 1. FRS Heated Wind Tunnel," Fire Safety Journal, Vo1. 12 (1987), p. 51. 
5. Heskestad, G. and Bill, R.G., "Quantification of Thermal Responsiveness of Automatic Sprinklers - RTI, Etc.," Fire Detection and Suppression Symposium, Society of Fire Protection Engineers, Linthicum Heights, Maryland, March 9-11, 1987.

6. Evans, D.D. and Madrzykowski, D., "Characterizing the Thermal Response of Fusible-Link Sprinklers," NBSIR 81-2329, National Bureau of Standards, Washington, D.C., August 1981.

7. Pepi, J.S., "Design Characteristics of Quick Response Sprinklers," Grinnell Fire Protection Systems Company, Providence, Rhode Island, May 1986.

8. Pepi, J.S., "Relationship Between Thermal Response and Fire Suppression Characteristios of Automatic Sprinklers in a Wet-Pipe System," Fire Detection and Suppression Symposium, Society of Fire Protection Engineers, Linthicum Heights, Maryland, March 9-11, 1987.

9. Heskestad, G. and Bill, R.G., Jr., "Conduction Heat-Loss Effects on Thermal Response of Automatic Sprinklers," FMRC J.I. ONOJ5.RU/ON1J6.RU, Factory Mutual Research Corporation, Norwood, Massachusetts, September 1987.

10. McCaffrey, B.J. and Heskestad, G., "A Robust Bidirectional Low-Velocity Probe for Flame and Fire Application," Combustion and Elame, Vol. 26 (1976), p. 125.

11. Heskestad, G., "A Fire Products Collector for Calorimetry into the MW Range," FMRC J.I. OC2E1.RA, Factory Mutual Research Corporation, Norwood, Massachusetts, June 1981.

\section{SYMBOLS}

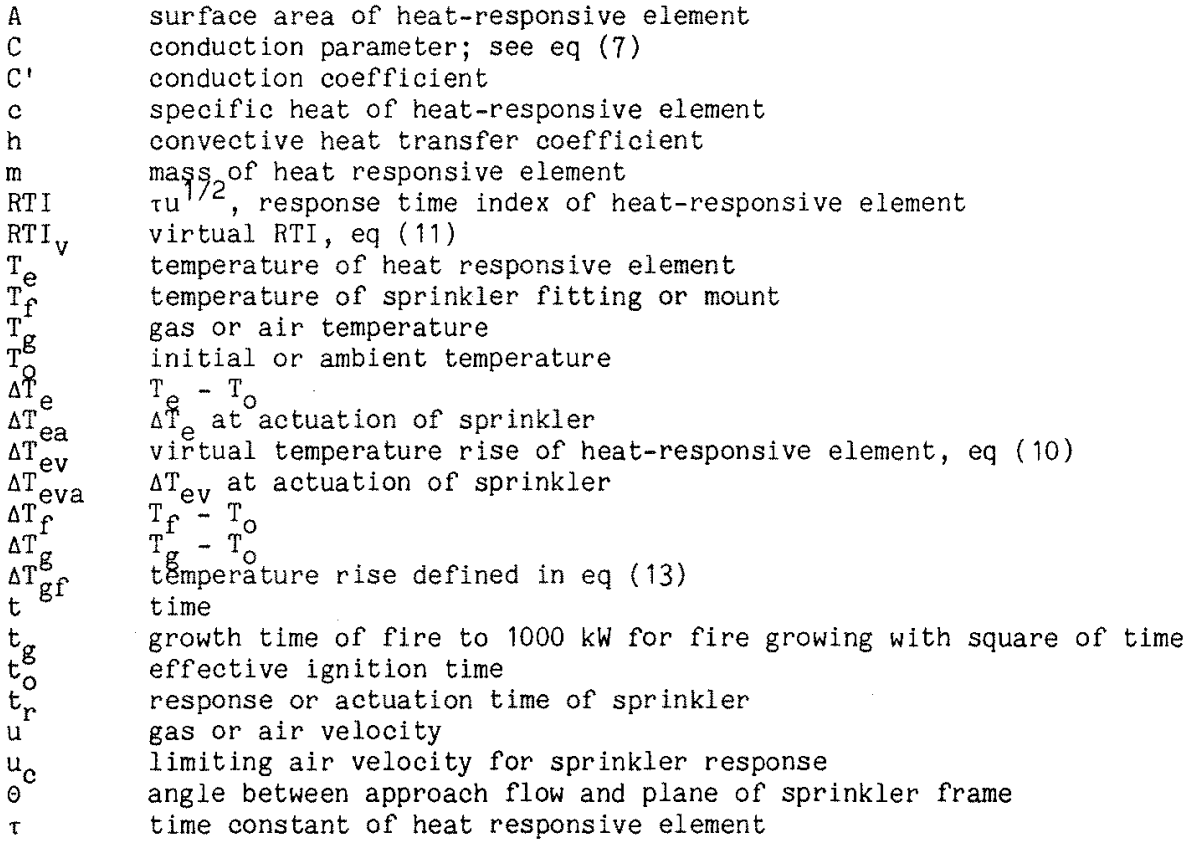

